\title{
Conflicto de intereses en sociedades que negocian sus acciones en el mercado de valores
}

\section{Conflict of interest in companies trading in their shares stock market}

\author{
Camilo E. Quiñónez Avendaño \\ Abogado por la Universidad Autónoma de Bucaramanga (Col.); especialista en Derecho Comercial por la Universidad \\ Externado de Colombia - Universidad Autónoma de Bucaramanga (Col.); especialista en Derecho Empresarial por la \\ Universidad Autónoma de Bucaramanga (Col.); magister en Derecho Económico por la Universidad Externando de \\ Colombia; doctorado (en curso) Universidad Externando de Colombia. \\ Correo electrónico: equinone@unab.edu.co
}

\section{Resumen}

En el presente artículo se publica una parte de la investigación titulada "Conflicto de intereses en sociedades que negocian sus acciones en el mercado de valores colombiano", cuyo objetivo general es analizar el desarrollo legal que el derecho colombiano ofrece frente al manejo de los conflictos de interés presentes en sociedades que negocian sus acciones en el mercado de valores. La investigación de la cual forma parte este contenido es una investigación jurídica, exploratoria que hace uso de la descripción y el análisis de un fenómeno jurídico de derecho societario con impacto en el mercado de valores.

Palabras clave: Conflictos de interés, administradores de sociedades anónimas, separación entre propiedad y control.

Abstract

In this article a part of the research entitled Conflict of interests in companies trading their shares on the Colombian stock market is published, whose overall objective is to analyze the legal development that Colombian law provides against the management of conflicts of interest present in companies trading their shares on the stock market. The research which is part of this content is legal research, exploratory making use of the description and analysis of a legal phenomenon of corporate law with an impact on the stock market.

Keywords: Conflicts of interest, managers of corporations, separation of ownership and control.

Résumé

Dans cet article, une partie de la recherche intitulé «Conflit d'intérêts dans les sociétés de commerce de leurs actions sur le marché boursier colombien est publié, dont l'objectif global est d'analyser l'évolution juridique que la loi colombienne prévoit contre la gestion des conflits de intérêt présent dans les sociétés de commerce de leurs actions sur le marché boursier. La recherche qui fait partie de ce contenu est la recherche juridique, exploratoire faisant usage de la description et de l'analyse d'un phénomène juridique du droit des sociétés ayant un impact sur le marché boursier.

Mots-clés: Conflits d'intérêts, les gestionnaires des sociétés, la séparation de la propriété et le contrôle.

Recibido: 30 de marzo de 2015; Aprobado: 10 de junio de 2015 



\section{Conflicto de intereses en sociedades que negocian sus acciones en el mercado de valores ${ }^{*}$}

Camilo E. Quiñónez Avendaño

\section{INTRODUCCIÓN}

La sociedad anónima es el paradigma o modelo de sociedad que acude a los mercados de valores en busca de financiación, a través de la venta de unidades de participaciones en su capital social llamadas acciones. Brunetti (2001) reconoce que este tipo de sociedades es uno de los instrumentos insustituibles en la economía, por cuanto hace posible la reunión de notables masas de ahorro en empresas en las que ninguna fortuna privada sería suficiente, o en las que el individuo no tendría la audacia de introducirse en atención a comprometer recursos de su patrimonio; además, ella ofrece una doble ventaja, de una parte, limita la responsabilidad del socio por las obligaciones sociales a la suma aportada, y de otra, existe la posibilidad de enajenar el título que representa su participación, sin que por ello se altere la consistencia del patrimonio de la sociedad.

En el derecho societario como formas o subtipos de la sociedad anónima se identifican las sociedades abiertas y cerradas, como especies de sociedades anónimas en las que la organización social, los conflictos de intereses entre socios y la relación entre estos y los administradores de la sociedad son muy diversos.

Cuando la sociedad anónima acude al mercado de valores se le califica como sociedad cotizada ${ }^{1}$, sociedad anónima bursátil ${ }^{2}$, sociedad inscrita ${ }^{3}$, o emisor de valores ${ }^{4}$, o con la expresión genérica: sociedad que negocia sus acciones en el mercado de valores. Independientemente de su denominación, uno de sus rasgos distintivos es la separación entre la propiedad y el control.

El fenómeno societario de la separación entre la propiedad y el control característico de las sociedades que negocian sus acciones en el mercado de valores

* Este artículo hace parte de la investigación: "Los conflictos de interés en sociedades que negocian sus acciones en el mercado de valores colombiano". El proyecto se inició el 20 de agosto de 2013 y concluyó el 20 de agosto de 2014. Código C34003 Dirección de Investigaciones de la Universidad Autónoma de Bucaramanga - UNAB. Financiación UNAB.

1 Ley del mercado de valores de España de 1998.

2 Ley del mercado de valores de México (2006).

3 Ley 964 de 2005 vigente en Colombia.

4 La Ley 964 de 2005 la utiliza como una expresión genérica que comprende otros emisores de valores que no son sociedades anónimas. 
se refiere a la gestión de los negocios en aquellas sociedades donde sus accionistas solo tienen una limitada participación y control indirecto en las decisiones de quienes son sus administradores. El estudio de este fenómeno reclamará distinguir entre sociedades donde existe dispersión de la propiedad accionaria y sociedades donde existe concentración de esta. En las primeras, los accionistas no tienen el control de las decisiones de los administradores, mientras estos tienen el control de la sociedad pero no participan de sus beneficios; en las que existe concentración de la propiedad accionaria hay identidad entre los dueños y los administradores quienes son los encargados de las decisiones y son beneficiarios de las utilidades que ella genera.

El fenómeno descrito hace que en el interior de las sociedades se presenten tensiones en la relación entre accionistas y el ejercicio del control sobre los administradores; entre accionistas mayoritarios y accionistas minoritarios, y entre la sociedad y los grupos de interés (stakeholders) de los que forman parte empleados, acreedores, clientes y agencias de supervisión.

Las tensiones originadas en la separación entre propiedad y control han despertado el interés del regulador colombiano a diseñar estrategias, instrumentos o figuras jurídicas que ayuden a prevenir, solucionar, disminuir los efectos o sancionar los abusos derivados del ejercicio del poder; contenidas principalmente en el derecho societario y de manera particular o específica en el derecho del mercado de valores - DMV.

\section{DEFINICIÓN DE CONFLICTO DE INTERESES}

En el derecho societario no se define conflicto de intereses, es en el derecho del mercado de valores - DMV donde se ha formulado una definición que guía el presente estudio que complementa el alcance de la figura formulado por organismos nacionales entre los que se encuentra la Superintendencia de Sociedades, Superintendencia Financiera de Colombia y Bolsa de Valores de Colombia.

En el DMV área especializada del derecho económico, en la cual se regulan las relaciones que se originan con ocasión de la negociación sobre valores, ya en el mercado bursátil o en el mercado extrabursátil se plantea una definición construida dentro del marco de las relaciones que se dan entre los intermediarios de valores y los inversionistas. Si bien, el tema central de esta investigación son los conflictos originados en las sociedades que negocian sus acciones en el mercado de valores, la definición legal que se presenta sirve como punto de partida. Así, en DMV el conflicto de interés

... es una situación en virtud de la cual una persona en razón de su actividad se enfrenta a distintas alternativas de conducta con relación a intereses incompatibles, ninguno de los cuales puede privilegiar en atención a sus obligaciones legales o contractuales ${ }^{5}$.

5 Decreto 2555 de 2010 artículo 7.6.1.1.2. Esta definición había sido adoptada desde 1995 por la Resolución 1200 de 1995. 
De manera particular, y en el contexto del derecho societario, la Superintendencia de Sociedades dentro de sus funciones de inspección, vigilancia y control ha definido los conflictos de interés como

... una figura autónoma en la cual un administrador tiene que decidir entre dos intereses contrapuestos: uno, el propio y otro el de la sociedad, caso en el cual debe contar con autorización para adelantar la gestión o sustraerse de la misma ${ }^{6}$.

Sus planteamientos permiten identificar la relación jurídica dentro de la cual se presentan, pone de presente un acontecimiento que ocurre en el interior de una sociedad anónima y la concibe como “... una situación en la que el interés particular de los administradores se contrapone con los intereses de la sociedad que administran"7.

Dado que no existe en el ordenamiento jurídico societario una disposición que señale las situaciones típicas de conflictos societarios, la Superintendencia de Sociedades aporta unos elementos de análisis para teorizar a cerca de las situaciones de conflictos. Considera este organismo que "existe conflicto de interés cuando no es posible la satisfacción simultánea de dos intereses, a saber: el radicado en cabeza del administrador y el de la sociedad, bien porque el interés sea de aquel o de un tercero".

En el campo especializado en valores, la Superintendencia Financiera de Colombia toma algunos elementos de la construcción legal y de los planteamientos de la Superintendencia de Sociedades con el fin de proponer, en el campo financiero, el alcance de este concepto jurídico. En la intelección de este organismo:

se entiende por conflictos de interés, las situaciones de interferencia entre esferas de interés, en las cuales una persona podría aprovechar para sí o para un tercero las decisiones que él mismo tome frente a distintas alternativas de conducta en razón de la actividad misma que desarrolla y del especial conocimiento que tenga y cuya realización implicaría la omisión de sus obligaciones legales, contractuales o morales a las cuales se halla sujeto"9.

De igual manera, la Bolsa de Valores de Colombia, como un centro especializado de negociación en valores, organismo privado e institución a través de la cual se realizan las transacciones sobre valores considera que "el conflicto de intereses constituye una situación de impedimento para la persona que se enfrenta a dicha situación, lo que le impone el deber de abstenerse de actuar"10.

Superintendencia de Sociedades. Oficio 220-066699 (mayo 26 de 2011).

Superintendencia de Sociedades. Oficio 220-015289 (marzo 11 de 2012).

Superintendencia de Sociedades. Circular Externa 20 de noviembre 4 de 1997.

9 Superintendencia Financiera de Colombia. Concepto No. 95017190-0 del 15 de mayo de 1995. Superintendente Delegado para Instituciones Financieras y Concepto 2007059749-001 del 28 de diciembre de 2007.

10 Resolución 41 de Marzo 23 de 2006 
Las definiciones que constituyen el marco de referencia para este estudio coinciden en identificar elementos del conflicto de intereses: la presencia de una relación entre dos extremos, esto es, un administrador y un administrado, o en su caso, un mandante y un mandatario y la existencia de intereses contrapuestos. Solo en la comprensión de la figura por parte de la BVC se destaca que ante esta situación el administrador o el mandatario tiene un deber de abstención.

De igual forma, las definiciones transcritas ponen de presente que para cualquier análisis es necesario identificar o reconocer que existe un interés de los administradores y un interés social o interés de la sociedad. Por interés social entendemos el interés del sujeto sociedad, distinto de las personas que lo componen y de los factores humanos, materiales, de coyuntura económica y social que la condicionan o afectan, a veces como elementos instrumentales, $\mathrm{y}$, en fin, le permiten su desarrollo exitoso o no (Morgestein, 2011).

\section{SEPARACIÓN DE PROPIEDAD Y CONTROL}

La sociedad anónima es el tipo societario característico de las sociedades donde predomina el factor capital, las regulaciones de países como Argentina, Italia, Estados Unidos de América y Colombia la presentan como una estructura impersonal en la que hay una separación entre la titularidad del capital y el control. Esta sociedad puede estar manejada por individuos que nada tienen que ver con la propiedad de las acciones en la que se divide el capital y bajo la denominación de managers manejan la riqueza de otras personas llamadas inversionistas (Córdoba, 2000).

En las sociedades de capital abiertas se presenta una estructura caracterizada por la dispersión del capital que se manifiesta por la presencia de un número de accionistas mayoritarios que no tiene en cuenta a los minoritarios o a aquellos que son accionistas indirectos por vía de fondos de inversión.

Esta característica produce consecuencias sobre el funcionamiento de los órganos de dirección, administración y representación, dado que no hay ningún accionista que pueda, por sí solo, superar los votos que controlan o manipulan los administradores y en consecuencia, el control efectivo de la sociedad pasa a tales administradores.

La transferencia de control se acentúa por distintos elementos. En primer lugar, la creciente complejidad y tecnificación de la vida empresaria implica que los accionistas no tienen la capacidad fáctica suficiente como para tomar decisiones informadas sobre las cuestiones empresariales, lo que hace que deleguen la toma de esas decisiones en los administradores. En segundo lugar, la participación activa en las decisiones de una gran empresa implica altos costos de asesoramiento y obtención de información, que un accionista individual difícilmente está dispuesto a incurrir (Cabanellas, 2009).

En el ámbito colombiano, esta separación entre propiedad y control no se muestra de manera explícita en la regulación, ello se extrae de los rasgos distintivos de la sociedad anónima, que ponen de presente una sociedad donde predomina el factor capital. 
Por sociedades de capital, en Colombia, entendemos aquellas formadas intuitu $r e i$, es decir, aquellas en las que en su formación predomina el factor real o factor capital. En ellas una vez efectuados los aportes, los asociados pasan a la penumbra y son inadvertidos o carecen de importancia para los terceros, en razón a que solamente responden hasta concurrencia de sus respectivas aportaciones. Es la compañía la que responde hasta el límite de su patrimonio por las obligaciones que contraiga en desarrollo de su actividad social. En ellas, las obligaciones de los socios y sus derechos pertenecen a la esfera interna de la sociedad, no trascienden a los terceros que negocian con ella, y los accionistas de hoy pueden ser distintos de los de ayer y de los de mañana (Narváez, 2002).

En la organización y estructura interna de la sociedad anónima existe un órgano de dirección, que es la asamblea general de accionistas, uno de administración denominado junta directiva, y uno de representación que usualmente recibe la denominación de gerente. Esta separación muestra que no todos los accionistas participan de la administración de los negocios sociales, aun cuando tienen vocación para formar parte de la junta directiva. La separación que aquí se describe es la que justifica la existencia de un revisor fiscal, cuya función primordial es controlar la actividad de los administradores.

La junta directiva se elige por el sistema de cociente electoral, figura con la cual se pretende que los distintos grupos de accionistas puedan formar parte del órgano de administración, sin embargo, permite que de la administración solo formen parte quien detente la mayoría absoluta en situaciones donde hay concentración de capital o por el grupo que logre consolidar una mayoría relativa cuando el capital esté disperso (Reyes, 2006).

Es en este contexto de separación de funciones de dirigir, administrar y representar donde se estudian los conflictos de interés, para lo cual se fija como premisa del presente estudio que "los administradores defienden profesionalmente intereses ajenos y prometen realizar la gestión negocial postergando los intereses propios y no bajo preferencias subjetivas de otros intereses ajenos" (Hopt, 2010, p. 154).

\section{ADMINISTRADORES DE SOCIEDADES ANÓNIMAS EN EL DERECHO COLOMBIANO}

Conforme a la teoría organicista de la persona jurídica societaria, la sociedad anónima es un ente integrado por órganos legales jerarquizados, que están autorizados, ya para expresar la voluntad colectiva, para ejecutarla ante terceros o para realizar cualquier actuación orientada a conseguir la finalidad de la persona jurídica (De Solá, 1963). Así, la asamblea general de accionistas es el órgano de dirección; la junta directiva el órgano de administración; el representante legal es el órgano encargado de la ejecución o gestión interna y externa, y el revisor fiscal es el órgano de fiscalización. 
Administrar es manejar, dirigir y gobernar bienes y negocios de otro, ordenar económicamente los medios disponibles y usar de ellos en la forma conveniente. En el derecho colombiano la expresión "administradores de sociedades" tiene una cobertura diferente si se analiza en la organización y estructura interna o frente al régimen de responsabilidad civil de los administradores. En el primer contexto, solo son administradores los miembros principales y suplentes de la junta directiva ${ }^{11}$; en el segundo, la expresión administradores es más amplia por cuanto se hace extensiva al representante legal, al liquidador, al factor, a los miembros de juntas o consejos directivos y a quienes de acuerdo con los estatutos ejerzan o detenten esas funciones ${ }^{12}$.

El estudio de conflictos de interés en sociedades que negocian sus acciones en valores se ubica en el segundo contexto, lo que significa que no solo se aplica a miembros de junta directiva. Estos administradores actúan en nombre e interés de terceras personas, razón por la cual se les impone la carga de obrar de buena fe, con lealtad y con la diligencia de un buen hombre de negocios y deben ejecutar sus actuaciones en interés de la sociedad, teniendo en cuenta los intereses de sus asociados, y tienen como deber "abstenerse de participar por sí o por interpuesta persona en interés personal o de terceros, en actividades que impliquen competencia con la sociedad o en actos respecto de los cuales exista conflicto de intereses, salvo que obtengan autorización de la junta de socios o asamblea general de accionistas ${ }^{13}$.

Las actuaciones del administrador guiadas por la buena fe reclaman rectitud, honradez y sanas intenciones en el desempeño de sus funciones; la diligencia implica ser cuidadoso y adoptar decisiones con conocimiento e ilustración sobre los efectos de cada acto, y la lealtad reclama al administrador actuar de la forma que más convenga a la sociedad, esto es, actuar en interés de la sociedad.

Para fijar el alcance de interés social, esta investigación toma como referente los postulados formulados por la teoría institucionalista ${ }^{14}$, conforme a la cual el interés de la sociedad va más allá del interés personal de los socios y se identifica con el interés de la empresa en sí misma, es decir, con el interés de la eficiencia productiva de la empresa, considerada como un instrumento del desarrollo económico general, mientras el interés de los socios se pone en posición subordinada y marginal. Esta teoría estudia el interés social en las relaciones internas y externas de la sociedad por acciones. En el ámbito interno de la sociedad estudia la relación entre el capital directivo y los accionistas minoritarios y sugiere que la sociedad por acciones debe disponer de un "ejecutivo" fuerte capaz de interpretar de modo autónomo las exigencias del manejo de la empresa; de un orden administrativo sustraído al poder directivo de la asamblea, no influido por el vehemente deseo de altos dividendos de

11 Artículos 434 a 439 del Código de Comercio Colombiano.

12 Artículo 22 de la Ley 222 de 1995.

13 Artículo 23 numeral 7 de la Ley 222 de 1995.

14 Esta teoría fue formulada en Alemania después de la Primera Guerra Mundial y ha sido difundida en Italia. En Alemania fue conocida como Unternehmen an sich y encuentra correspondencia con la teoría formulada en EE. UU. denominada corporate philosophy. Fue formulada por P.G. Jaeger. 
los socios. En las relaciones externas de la sociedad el interés de la empresa es un interés superior que va más allá del interés de todos los socios incluidos los socios mayoritarios, el interés social es un interés común a los socios y a los dependientes o empleados de la sociedad frente al cual debe sucumbir todo interés particular, inclusive el de los grupos directivos de la sociedad.

Los parámetros de lealtad, diligencia y buena fe guían la actuación de los administradores independientemente de si la sociedad que administran participa o no en el mercado de valores como emisor. Es el derecho societario el área encargada de fijar estos parámetros. El derecho del mercado de valores agrega unos elementos especiales en lo relacionado con las sociedades que ofrecen sus valores en el mercado, que denominamos sociedad inscrita, elementos que no están relacionados con los deberes de los administradores sino con la integración de la junta directiva de las sociedades.

En primer lugar, la junta directiva de la sociedad inscrita tiene como deber considerar, responder y motivar por escrito las propuestas presentadas a las juntas directivas de las sociedades inscritas ${ }^{15}$, siempre que no tengan por objeto temas relacionados con secretos industriales o información estratégica para el desarrollo de la compañía. Con esta exigencia, el DMV colombiano crea un mecanismo que facilita la participación de los accionistas en el gobierno del ente societario, para lo cual no distingue entre sociedades caracterizadas por una gran concentración de la propiedad accionaria o por una dispersión accionaria. Es posible que el tinte protector de esta medida encuentre en las sociedades con dispersión accionaria un escenario apto para cumplir sus fines, toda vez que en las primeras, el accionista o accionistas que ejercen control siempre van a estar muy cerca del ejercicio de la administración que les permite conocer al detalle información societaria sin necesidad de utilizar el mecanismo que aquí se estudia.

Desde el punto de vista práctico, se advierte que los temas sobre los cuales pueden formularse estas propuestas son de diversa índole, generando a la junta directiva una carga operativa que puede cambiar el rumbo o aplazar decisiones en interés de la organización. La advertencia puede tener otro elemento para analizar relacionado con la posibilidad de impugnar esta decisión, ya que al ser una decisión de la junta directiva queda sometida a controversias judiciales que pueden influir en el precio de las acciones inscritas.

En segundo lugar, la sociedad inscrita debe cumplir normas imperativas especiales sobre la integración de la junta directiva, que imponen entre otras cargas: tener un mínimo de 5 integrantes y un máximo de 10 principales con suplentes, de los cuales el $25 \%$ deberá ser independiente; no tener suplentes numéricos; que los suplentes de los miembros principales independientes tengan el mismo carácter y que el representante legal no puede ser presidente de la junta directiva.

15 Artículo 39 Ley 964 de 2005. 
En la exposición de motivos de la Ley 964 de 2005 se expresó que con este deber se pretende incrementar los parámetros de eficiencia de las juntas directivas como la máxima autoridad administrativa de la sociedad, así como los niveles de protección de los intereses de la sociedad por encima de los intereses de los accionistas controlantes y de los administradores vinculados con aquellos, lo que finalmente redunda en un mayor nivel de protección de los accionistas minoritarios, de los acreedores, de la comunidad de influencia del emisor y en general del público.

Alámbito de protección fijado en la exposición de motivos ponemos a consideración de una parte, que la presencia de miembros independientes, es un mecanismo que fortalece la administración y crea un mecanismo de pesos y contrapesos en el interior de la sociedad; de otra, la prohibición al representante legal impedirá que utilice su presencia en la junta directiva para formalizar o legalizar lo que probablemente han llevado a la práctica, pueden persuadir a la junta directiva a que apruebe o ratifique algunas actuaciones.

\section{TIPOLOGÍA DE CONFLICTOS DE INTERÉS}

Los conflictos que se presentan en el interior de sociedades mercantiles pueden ser de distintos tipos, así, podemos identificar conflicto entre administradores y accionistas; conflicto entre accionistas mayoritarios y accionistas minoritarios; y conflicto entre accionistas de la sociedad y acreedores de la sociedad.

Todos los conflictos tienen en común "problemas de agencia" o problemas de mandato, de los que surgen dificultades, dado que el bienestar de una de las partes denominada mandante o principal, depende de las acciones adelantadas por un tercero, denominado el mandatario o agente (Reyes, 2012).

La caracterización de los conflictos societarios se construye a partir de la noción de conflicto de intereses que se presenta cuando un sujeto representa los intereses de dos sujetos distintos, de modo que no puede defender los intereses de uno de ellos sin perjudicar los intereses del otro. Bajo esta definición, se tiene que los intereses en conflicto pueden ser los del sujeto que actúa frente a los de otra persona a la que él representa o bien los intereses de dos sujetos distintos a quien actúa.

La noción de conflicto requiere que exista un sujeto en una relación derivada de representación, obligado a defender los intereses de su representado y para defender esos intereses tendría que actuar en contra del interés propio o de una tercera persona. Bajo esta perspectiva podemos identificar unos elementos que caracterizan una situación de conflicto:

- Sujeto calificado: un sujeto que por disposición legal o contractual está obligado a defender intereses de otro.

- Existencia de intereses diversos: que ese sujeto calificado tenga un interés propio o esté obligado a defender intereses de otra persona.

- Colisión o contraposición de intereses: que la actuación del sujeto calificado perjudique intereses propios (conflicto directo) o de un sujeto distinto a 
aquel del que defiende sus intereses (conflicto indirecto). Se destaca que no existirá contraposición de intereses cuando los intereses que concurren en un asunto son coincidentes, paralelos o comunes, incluso distintos siempre y cuando sean compatibles. Se requerirá que la existencia de los distintos intereses ponga en evidencia un potencial daño para el representado.

Estos tres elementos contribuyen a determinar cuándo nos encontramos frente a conflicto de intereses. De manera que no se requiere un catálogo declarado en la ley, en estatutos, en normas de buen gobierno corporativo o cualquier disposición normativa para determinar las situaciones de conflicto.

El factor temporal puede permitir reconocer conflictos permanentes o conflictos ocasionales. Esto significa que pueden presentarse conflictos referidos a una situación permanente o a un determinado acto u operación económica. Si bien esta consideración no aporta un nuevo elemento que permita caracterizar el conflicto, sirve para reconocer que el derecho colombiano no distingue entre ambos y su regulación abarca unos y otros.

De igual forma, pueden presentarse conflictos de interés directos entre los administradores de la sociedad y conflictos de interés por interpuesta persona. Estos se presentan cuando "la compañía celebra operaciones con el cónyuge o compañero permanente del administrador, o las personas con análoga relación de afectividad"16.

El derecho colombiano no ofrece una definición legal de conflictos de interés ni presenta un listado de conflictos permanentes, ocasionales, directos o por interpuesta persona. Existe un vacío, desde la perspectiva del derecho positivo, que se llena con el análisis de cada caso concreto a partir de los elementos que caracterizan una situación de conflicto.

A continuación se presentan algunas situaciones de hecho ocurridas en el interior de una sociedad, con el fin de ilustrar sobre las distintas manifestaciones que puede tener el conflicto de intereses, bajo el entendido que no hay un catálogo normativo sobre situaciones de conflicto, lo que reconocemos son situaciones y actuaciones de los administradores en las que están presentes los conflictos de interés, que de inmediato activan los mecanismos legales de protección.

\section{Caso Loyalty Marketing Services de Colombia S.A.S. ${ }^{17}$ - Autocontratación y contratación con cónyuge}

Shirley Natalia Ávila Barrios representante legal suplente de Loyalty Marketing Services de Colombia S.A.S. en el periodo comprendido entre 2 de junio de 2009

16 Oficio 220-140389 de noviembre 27 de 2012 de la Superintendencia de Sociedades.

17 Sobre este caso se pronunció la Superintendencia de Sociedades en ejercicio de funciones jurisdiccionales mediante Sentencia 800-29 de mayo 14 de 2013, proceso verbal sumario radicado bajo el número 2013-801-076. Este fallo declaró el incumplimiento de los deberes que correspondían a la administradora y condenó en abstracto al pago de perjuicios, dado que el demandante no probó su cuantía. 
y 30 de mayo de 2013. Durante este periodo participó activamente en la gestión administrativa de la sociedad, celebró distintos negocios en representación de la mencionada sociedad entre los que se encuentran contratos con entidades financieras, con empleados y con proveedores; también preparó estados financieros y orientó estrategias comerciales de la compañía.

Entre sus actuaciones como administradora se encuentra:

- Contrato de prestación de servicios con Fredy Antonio Rodríguez Ardila, con quien tenía vínculo matrimonial vigente al momento de celebrarse el contrato.

- Préstamos a su favor con recursos de la compañía Loyalty Marketing Services de Colombia S.A.S., para la compra de un vehículo personal y múltiples giros provenientes de las cuentas bancarias de la compañía a favor de la señora Ávila Barrios.

- Utilización de cupos de crédito aprobados por Bancolombia S.A a favor de Loyalty Marketing Services de Colombia S.A.S. con cargo a la tarjeta de crédito de la que es titular la compañía.

En las tres actuaciones se ponen de presente situaciones que evidencian conflicto. En la primera, el vínculo matrimonial constituye importante incentivo para que la señora Ávila Barrios salvaguardara el interés de un tercero y le imponía la obligación de solicitar autorización a la asamblea general de accionistas para suscribir dicho contrato; en la segunda, tampoco obtuvo autorización de los socios para autocontratar e infringió tanto la prohibición de actuar en situaciones de conflicto, así como el deber de lealtad, aun cuando al momento de analizar su conducta ya había pagado una parte del préstamo; y en la tercera, nuevamente infringe el deber de lealtad dado que se le reprocha utilizar para beneficio propio instrumentos que solo podía utilizar para la gestión de los negocios de la compañía.

\section{Empresa de Energía de Cundinamarca S.A. ESP ${ }^{18}$ - Administrador común en dos sociedades}

Ricardo Roa Barragán miembro principal de la Junta Directiva de la Empresa de Energía de Cundinamarca S.A. E.S.P. ocupaba ese mismo cargo en Codensa S.A. E.S.P. Ambas organizaciones celebraron un contrato de asistencia técnica en virtud del cual Codensa S.A. E.S.P prestaba servicios a la Empresa de Energía de Cundinamarca. En reunión de junta directiva de esta última compañía, el señor Roa Barragán deliberó y votó favorablemente la propuesta de dar por terminado el contrato de asistencia técnica. Se destaca que el voto del señor Roa fue determinante

18 Hechos tomados de auto proferido por la Superintendencia de Sociedades de fecha mayo 19 de 2014 dentro del proceso verbal en el que es demandante Aurelio Bustilho de Olivera contra la Empresa de Energía de Cundinamarca S.A. E.S.P. Al momento de elaboración de este trabajo de investigación la sentencia que dirime el conflicto no ha sido publicada por parte de la Superintendencia de Sociedades. 
para aprobar la decisión, dado que hubo cuatro votos a favor y tres abstenciones. Esto significa que de descontarse el voto emitido por el administrador cuya conducta se cuestiona, no se habría obtenido la mayoría necesaria para aprobar la decisión.

El señor Ricardo Roa Barragán al tener su doble calidad representaba intereses contrapuestos y debía obtener autorización de la Asamblea General de Accionistas de la Empresa de Energía de Cundinamarca S.A. E.S.P. para poder participar en cualquier gestión relacionada con la terminación del contrato de asistencia técnica, autorización que no solicitó.

\section{Empresa de Energía de Bogotá S.A. ESP ${ }^{19}$ - Vínculo laboral o societario}

La Empresa de Energía Eléctrica de Bogotá celebró un acuerdo de inversión con Codensa S.A. ESP. Acordaron que esta compañía apoyaría a la Empresa de Energía de Cundinamarca S.A. ESP (EEC S.A.) en el desarrollo de su objeto social y fijaron las reglas para administrar su inversión conjunta en las sociedades Distribuidora Eléctrica de Cundinamarca S.A. ESP (DECSA) y Empresa de Energía de Cundinamarca S.A. ESP.

Los señores Paulo Orozco y Aurelio Bustilho, miembros de la Junta Directiva de las sociedades DECSA S.A. ESP y EEC S.A. ESP, están vinculados laboralmente a Codensa y a empresas de su mismo grupo económico; también, el representante legal de EEC S.A. ESP tiene vínculo directo con la organización Codensa. Estas vinculaciones hacen que en todos los negocios que hayan celebrado para la ejecución del acuerdo de inversión estén inmersos en un conflicto de intereses, en especial en el contrato de asistencia técnica a EEC S.A.

\section{Procinal Bogotá Ltda. y Cineworld S.A.S. ${ }^{20}$ - Administrador común en dos sociedades}

Rafael Alfonso Gaviria es representante legal de Procinal Bogotá Ltda. y socio minoritario, además es socio único y representante legal de Cineworld S.A.S. En tal calidad, celebra diversos negocios entre las dos sociedades y transfiere derechos de propiedad sobre diversos inmuebles al Banco de Occidente S.A. a fin de que esta entidad financiera celebrara una operación de leasing inmobiliario con Cineworld S.A.S. Además, dispuso de recursos monetarios de Procinal Bogotá Ltda. para pagar

19 Datos tomados de auto 801-11097 de agosto 5 de 2014 dictado dentro del proceso verbal sumario de la Empresa de Energía Eléctrica de Bogotá S.A. ESP contra Codensa S.A. ESP radicado bajo el número 2014-801-068. Mediante este auto se decide la procedencia de medida cautelar en procesos societarios. Al momento de hacer el estudio de caso no se ha publicado la sentencia que ponga fin a esta controversia.

20 Datos tomados de auto 801-17880 de diciembre 4 de 2014 dictado dentro del proceso verbal sumario de Londoño Hermanos y Compañía Ltda. contra Rafael Alfonso Gaviria, Procinal Ltda. y Cineworld S.A.S. radicado bajo el número 2014-801-235. Mediante este auto se decide la procedencia de medida cautelar de inscripción de demanda en procesos societarios. Al momento de hacer el estudio de caso no se ha publicado la sentencia que ponga fin a esta controversia. 
obligaciones financieras a cargo de Cineworld S.A.S.; préstamos a favor de Rafael Alfonso Gaviria y pago de créditos personales con cargo a la sociedad en la que era socio minoritario.

\section{Vector Construcciones y Soluciones S.A.S. ${ }^{21}$ - Vínculo matrimonial}

Edward Alberto Rico Ávila, representante legal de la sociedad Vector Construcciones y Soluciones S.A.S, utilizó a la compañía Ingenieros Técnicos de Colombia S.A.S representada legalmente por su esposa para distraer las sumas que Minas Paz del Rio S.A pagaba a Vector Construcciones y Soluciones S.A.S.

En esta situación el vínculo matrimonial representa un conflicto de interés que compromete el juicio objetivo del representante legal al momento de transferir recursos a la sociedad en la que su esposa se desempeña como representante legal.

\section{SAC Estructuras Metálicas S.A. ${ }^{22}$ - Suministro de dinero por parte de los administradores a título de mutuo a favor de la sociedad}

Daniel Correa Senior y Francisco Correa Laverde fueron representantes legales conjuntos de la sociedad SAC Estructuras Metálicas S.A, durante este tiempo suministraron dinero a título de mutuo a favor de la sociedad para lo cual suscribieron pagarés en los que la sociedad es otorgante de la promesa de pagar y los administradores son los beneficiarios. Esta labor la hicieron alternándose la representación legal ${ }^{23}$. Además, se hizo la misma operación con Gloria Estella Gallo Pérez quien es cónyuge de Daniel Correa Senior.

En esta situación se presenta una contraposición entre los intereses de los mutuantes (administradores) y el mutuario (la sociedad), debido a que los administradores obtendrían un beneficio económico en interés personal y en interés del tercero cónyuge del administrador. En estas actuaciones no se solicitó la autorización del máximo órgano social.

21 Datos tomados de auto 801-3504 de febrero 27 de 2015 dictado dentro del proceso verbal sumario de Vector Construcciones y Soluciones S.A.S contra Edward Alberto Rico Ávila radicado bajo el número 2015-800-24. Mediante este auto se decide la procedencia de medida cautelar en procesos societarios. Al momento de hacer el estudio de caso no se ha publicado la sentencia que ponga fin a esta controversia.

22 Datos tomados de Sentencia 801-35 de julio 9 de 2013 proferida por la Superintendencia de Sociedades en el proceso verbal sumario de SAC Estructuras Metálicas S.A. contra José Daniel Correa Senior, Santiago Francisco Correa Laverde y Gloria Stella Gallo Pérez, proceso radicado bajo el número 2013-801-007.

23 Los pagarés emitidos a favor de Daniel Correa fueron suscritos por Santiago Francisco Correa en calidad de representante legal y los emitidos a favor de Santiago Francisco Correa fueron suscritos por Daniel Correa como representante legal. 


\section{MECANISMOS PARA ADMINISTRAR CONFLICTOS DE INTERÉS EN SOCIEDADES ANÓNIMAS}

\section{Adopción de normas de buen gobierno corporativo}

Bajo la denominación de gobierno corporativo o corporate governance se hace referencia a un conjunto de mecanismos de mercado, institucionales y normativos del que forman parte los instrumentos mediante los cuales se resuelven los conflictos entre participantes en el proceso productivo de un país, así como los mecanismos por medio de los cuales se tutela tanto a productores y financiadores y los canales de crecimiento de la empresa (Córdoba, 2000).

El gobierno corporativo es una figura nueva en el derecho societario, su origen se encuentra en Estados Unidos de América, donde se hacen esfuerzos por lograr que las estructuras jurídicas permitan un desarrollo eficiente de la actividad empresarial, bajo el entendido que las organizaciones societarias son el pilar en el que se apoya el funcionamiento y el crecimiento del sistema económico.

La Superintendencia Financiera de Colombia concibe el gobierno corporativo como un sistema, del cual forma parte un conjunto de normas y órganos internos, mediante el cual se dirige y controla la gestión de una persona jurídica, ya de forma individual o dentro de un conglomerado. Se concreta o materializa mediante unas normas privadas que definen derechos y responsabilidades, que fijan pautas dentro de las cuales interactúan los órganos de gobierno de una sociedad entre los que se destaca el máximo órgano de dirección, la junta o consejo directivo, los representantes legales y demás administradores, el revisor fiscal y los correspondientes órganos de control $^{24}$.

Este conjunto de normas al que conviene denominar normas de buen gobierno corporativo en el derecho colombiano son de adopción voluntaria por parte de las sociedades emisoras de valores. A estas sociedades les corresponde hacer un analizar de sus fortalezas y debilidades, para lo cual deben tener presente la forma en que son gobernadas y controladas, así como prever el cumplimiento de los deberes, responsabilidades, funciones y atribuciones de cada uno de los niveles de administración y representación.

Si bien, esta no es una exigencia legal ni es una disposición contenida en estatutos, es recomendable que las sociedades adopten estas normas de buen gobierno corporativo en busca de una participación activa y equitativa en la toma de decisiones. Estas normas podrían exigir juntas directivas más responsables, capacitadas y transparentes, permiten diseñar controles internos y asegurar los derechos de los inversionistas y de los grupos de interés relacionados con la compañía, a punto que logren evitar que algún interés particular prevalezca sobre el interés de la sociedad.

24 Documento conceptual de gobierno corporativo de la Superintendencia Financiera, elaborado en 2010 . 
Con estas normas se regularán los problemas de agencia presente en la administración societaria y se materializan en un marco autorregulatorio que garantiza confianza a los accionistas y cualquier aportante de recursos.

El marco autorregulatorio que se propone se origina en una tendencia internacional bajo directrices trazadas por la Organización Económica para la Cooperación y el Desarrollo (OCDE), quien considera la transparencia como un factor determinante para promover la inversión, por lo que ofrece apoyo para que se implemente un sistema de gobierno corporativo, a partir del "Principio de información y transparencia", en virtud del cual, el marco de gobierno corporativo debe asegurar la revelación oportuna y precisa de todas las cuestiones materiales, referentes a la corporación incluidos los resultados, la situación financiera, el desempeño, la propiedad y el gobierno de la compañía.

Las directrices de la OCDE se concretan en recomendaciones para los Estados a promover el uso de las normas de buen gobierno corporativo, para lo cual sugiere que el marco para el gobierno corporativo ${ }^{25}$ deberá:

- Promover la transparencia y eficacia de los mercados, ser coherente con el régimen legal y articular de forma clara el reparto de responsabilidades entre las distintas autoridades supervisoras, reguladoras y ejecutoras.

- Amparar y facilitar el ejercicio de los derechos de los accionistas.

- Garantizar un trato equitativo a todos los accionistas, incluidos los minoritarios y los extranjeros. Todos los accionistas deben tener la oportunidad de realizar un recurso efectivo en caso de violación de sus derechos

- Reconocer los derechos de las partes interesadas establecidos por ley o a través de acuerdos mutuos, y fomentar la cooperación activa entre sociedades y las partes interesadas con vistas a la creación de riqueza y empleo, y a facilitar la sostenibilidad de empresas sanas desde el punto de vista financiero.

- Garantizar la revelación oportuna y precisa de todas las cuestiones materiales relativas a la sociedad, incluida la situación financiera, los resultados, la titularidad y el gobierno de la empresa.

- Garantizar la orientación estratégica de la empresa, el control efectivo de la dirección ejecutiva por parte del Consejo y la responsabilidad de éste frente a la empresa y los accionistas.

En su declaración de principios de gobierno corporativo la OCDE hace un llamado a prevenir la aparición de conflictos de intereses y sugiere que el Consejo esté capacitado para realizar juicios de valor objetivos, lo que trae consigo independencia y objetividad frente a la Dirección.

25 Principios de Gobierno Corporativo de la OCDE 2004. Recuperado de http://www.oecd.org/daf/ ca/corporategovernanceprinciples/37191543.pdf. Fecha de consulta 18 de mayo de 2015. 
Es el derecho del mercado de valores la rama del derecho económico en la que se ha regulado el tema para los emisores de valores. En Colombia utilizamos la expresión "Código de Mejores Prácticas Corporativas de Colombia o Código País". La Superintendencia Financiera de Colombia, en Circular Externa 028 de 2007, impuso la obligación a los emisores de valores de diligenciar y remitir anualmente a la Superintendencia Financiera una encuesta mediante la cual se dé a conocer al mercado de valores la adopción de las recomendaciones del Código de Mejores Prácticas Corporativas de Colombia, también denominado en la citada circular "Código País", o la explicación de porqué no se ha adoptado determinada práctica.

Esta obligación se impone a todas las entidades que se encuentren inscritas o que tengan valores inscritos en el Registro Nacional de Valores y Emisores RNVE, excepto la Nación; los patrimonios autónomos fiduciarios, constituidos o no como fondo común; universalidades jurídicas resultantes de implementación de titularización hipotecaria por parte de entidades del sector solidario, asociaciones mutualistas de ahorro y crédito, cooperativas financieras, los fondos de empleados, el Fondo Nacional de Ahorro y cualesquiera otra entidad diferente de los establecimientos de crédito $^{26}$; las entidades territoriales, esto es, departamentos, distritos, municipios y territorios indígenas; los organismos multilaterales de crédito; los gobiernos extranjeros y las entidades públicas extranjeras; las sucursales de sociedades extranjeras y las entidades extranjeras.

El deber señalado se cumple a través del representante legal del emisor, quien es el encargado de diligenciar y transmitir a la Superintendencia Financiera de Colombia el contenido de la encuesta la que se acompaña de su firma digital ${ }^{27}$. Además la encuesta con sus respuestas debe ser publicada en la página web del emisor y mantener actualizadas las respuestas con la misma periodicidad con que se reporte a la superintendencia.

En cuanto a la oportunidad con que debe cumplirse este deber, la Circular comentada señala que la encuesta debe ser remitida entre el 2 y el 31 de enero del año siguiente a aquel en que va a revelar la adopción de prácticas de gobierno corporativo y la información que suministran las respuestas deben hacer referencia al periodo comprendido entre enero y diciembre del año inmediatamente anterior a su diligenciamiento, reporte y envío.

La debilidad de este instrumento para el manejo del conflicto de intereses radica en que son normas de adhesión voluntaria, que no tienen un carácter coercitivo y que son creadas por la misma Asamblea General de Accionistas quien declarará solo los conflictos de interés que conozca o desee y de presentarse el conflicto, el correctivo

26 Artículos 1 y 2 de la Ley 546 de 1999.

27 La firma digital es un valor numérico que se adhiere a un mensaje de datos, que se obtiene mediante un procedimiento matemático que permite determinar que tal valor se ha obtenido exclusivamente con la clave del iniciador y que el mensaje inicial no ha sido modificado. Mediante Ley 527 de 1999 se definió y reglamentó el uso de los mensajes de datos, del comercio electrónico y las firmas digitales en Colombia. 
lo adoptará la asamblea con posterioridad a su ocurrencia y de todas formas habrá necesidad de acudir a los mecanismos judiciales de declaración de nulidad absoluta de los contratos celebrados en situaciones que evidencien conflicto.

1. Obligación del administrador de poner de presente ante AGA la situación generadora de conflicto de interés.

Con el fin de evitar que se exteriorice las situaciones de conflicto de interés y que afecten la reputación de la compañía, información que de inmediato afectará los precios de los valores que negocian en el mercado, se sugiere administrar ${ }^{28}$ el conflicto de interés en el ámbito interno.

Corresponde a quien identifique que actúa en situación donde se presentan intereses contrapuestos, es decir, al administrador, convocar a la asamblea general de accionistas a una reunión extraordinaria. En la convocatoria a esta reunión señalará dentro del orden del día la solicitud de autorización para desarrollar la actividad que le representa conflicto de intereses.

Durante el desarrollo de la reunión el administrador debe suministrar toda la información que sea relevante para la toma de la decisión y de la determinación de autorizar la actuación deberá excluirse el voto del administrador en caso de que fuere socio.

Este mecanismo o instrumento supone que el administrador guiado por la diligencia, lealtad y buena fe, reconozca su actuación contraria al interés social y ponga en conocimiento la situación. La debilidad de este instrumento radica en que los socios no administradores dependen de la voluntad del administrador inmerso en el conflicto de intereses, que no siempre actuará conforme al deber explicado en este numeral.

\section{Intervención judicial}

La intervención de los jueces de la república o de los funcionarios administrativos con funciones jurisdiccionales es un mecanismo creado por el Derecho societario colombiano para contrarrestar los efectos que produce la actuación de los administradores societarios en situaciones de conflictos de interés, lo que significa que no opera de manera preventiva.

Son dos los contextos en los que podemos identificar la intervención judicial, de una parte, si es la Junta Directiva la que adopta una decisión ante una situación de conflicto de interés, y de otra parte, si es una actuación de un representante legal, en

28 El tema se plantea como una sugerencia dado que existen otros mecanismos para administrar los conflictos de interés. El que aquí se comenta se toma del Decreto Único Reglamentario 1074 de 2015. 
situación de conflicto de interés, que se concreta en la celebración de contratos. En uno u otro caso el instrumento a utilizar es la declaración judicial de nulidad absoluta de la decisión o del contrato celebrado, según el caso.

Cuando de controvertir decisiones de cuerpos colegiados al interior de sociedades se trata, la más inmediata solución, al interior del Derecho Societario es la impugnación de decisiones sociales. Sin embargo, este concepto jurídico fue creado en el Derecho colombiano para dejar sin efectos decisiones de la asamblea general de accionistas o de la junta de $\operatorname{socios}^{29}$. Esto significa que no puede aplicarse para atacar decisiones adoptadas por la junta directiva que actúe en contrariedad al deber de abstenerse de participar por sí o por interpuesta persona en interés personal o de terceros, en actos respecto de los cuales exista conflicto de intereses ${ }^{30}$.

La exclusión de este mecanismo no deja a la sociedad o a los socios sin la posibilidad legal de dejar sin efecto la decisión que contraría el deber. Existe la posibilidad de acudir a un trámite judicial para pedir la declaración de nulidad absoluta de esa decisión, dado que la actuación de la junta directiva contraría una norma imperativa. Esta contrariedad conforme a la regulación comercial colombiana, produce como efecto la nulidad absoluta del acto jurídico que en este caso es la decisión del cuerpo colegiado $^{31}$.

De otra parte, si lo que es objeto de estudio es la celebración de un contrato por parte del representante legal, en situación de conflicto de interés y sin haber obtenido la autorización de la asamblea general de accionistas, la contrariedad a la norma imperativa que impone deberes a los administradores produce como efecto la nulidad absoluta del contrato celebrado en estas condiciones.

\section{Autorización de la Asamblea General de Accionistas}

El máximo órgano social al adoptar la decisión no puede perder de vista que el bienestar de la sociedad es el objetivo principal de su trabajo y de su poder, razón por la cual habrá lugar a la autorización cuando el acto no perjudique los intereses de la compañía. Por tanto, para determinar la viabilidad de la misma, la junta o la asamblea evaluarán, entre otros, los factores económicos, la posición de la sociedad en el mercado y las consecuencias del acto sobre los negocios sociales. No sobra advertir que cuando el administrador tenga la calidad de asociado, deberá abstenerse de participar en la respectiva decisión y, en consecuencia, sus partes de interés, cuotas o acciones no podrán ser tomadas en cuenta para determinar el quórum, ni mucho menos la mayoría decisoria. Finalmente, si el máximo órgano social no imparte su autorización, el administrador deberá abstenerse de ejecutar los actos de competencia

29 Artículo 191 del Código de Comercio.

30 Artículo 23 numeral 7 de la Ley 222 de 1995.

31 Articulo 899 numeral 1 del Código de Comercio Colombiano. 
o aquellos generadores de la situación de conflicto. En caso de desacato, podrá ser removido de su cargo y estará sujeto a la responsabilidad de que trata el artículo 200 del Código de Comercio. Lo anterior, sin perjuicio de las sanciones de orden legal que hubiere lugar.

\section{Intervención de la Superintendencia de Sociedades}

Tratándose de sociedades sujetas a supervisión, esta Superintendencia puede entrar a pronunciarse en relación con la existencia de conflictos de interés, actos de competencia y utilización indebida de la información privilegiada, previa formulación de queja por quien se encuentre legitimado para hacerlo. En este caso, la Superintendencia luego de evaluar la información que le suministre el quejoso, así como la obtenida de manera oficiosa, procederá a formular los cargos respectivos al administrador a fin de garantizar tanto el debido proceso como su derecho de defensa.

Surtida esta actuación, la Superintendencia entrará a definir la situación concreta y si se estima que hay mérito, ordenará al administrador que se abstenga de realizar los actos generadores del conflicto y en caso extremo podrá ordenar la remoción de tal administrador, en los eventos previstos en la ley. La intervención de la Superintendencia de sociedades no se hace extensiva a declarar responsabilidad y efectos indemnizatorios, asuntos que son conocimiento de la justicia civil.

\section{CONCLUSIONES}

Las sociedades anónimas en Colombia siguen el modelo de sociedades de capital que participan en los mercados de valores mediante la emisión y venta de valores con el fin de obtener financiación. Su estructura legal caracterizada por la separación entre las funciones de dirección, administración y representación hace que no todos los socios participen de la administración de la compañía y en algunos eventos se permita la presencia de extraños en la administración de esta.

Sea que la sociedad anónima se administre por los mismos socios o por extraños, la presencia de seres humanos caracterizados por ser individualistas y maximizadores de utilidad hace que sea inherente a su funcionamiento la presencia de intereses individuales de los administradores e intereses de la sociedad.

El derecho colombiano reconoce esa característica de las sociedades anónimas y de manera general en el derecho societario se ha incluido dentro de los deberes de los administradores el deber de abstenerse de actuar en situaciones que impliquen un conflicto de intereses. En esta manifestación del derecho no hay una tipología de conflicto, solo se plantea el deber mencionado. Por esta razón se sugiere que el estudio de los conflictos de intereses no se realice a partir de un catálogo normativo, situación que convoca a analizar en cada caso concreto la presencia de tres elementos 
para determinar si la situación se enmarca dentro del conflicto. Estos elementos son la existencia de un sujeto calificado que por disposición legal o contractual está obligado a defender intereses de otro; la existencia de intereses diversos y que esos intereses sean contrapuestos.

Hay en el derecho colombiano un intento por contrarrestar los efectos que genera la actuación de administradores en situaciones que generan conflictos, mediante la creación de mecanismos legales como el gobierno corporativo, la intervención judicial, la intervención de organismos de inspección, vigilancia y control y de la asamblea general de accionistas. Todos ellos tienen en común que no pueden ofrecer un tratamiento preventivo a las situaciones de conflicto. De manera que, corresponde al emisor de valores, si desea evitar que la existencia de conflictos afecte su reputación en el mercado, y que incida de manera negativa en el valor de sus acciones, diseñar mecanismos para prevenir situaciones de conflicto de interés a partir de la ética, dado que el derecho colombiano no soluciona los problemas originados con las actuaciones que contraríen el deber de abstención de los administradores.

\section{REFERENCIAS}

Arrecha, M. (2009). La responsabilidad de los directores por interés contrario (particularmente en la sociedad anónima). En M. Arrecha, \& otros. La responsabilidad de los administradores en las sociedades y los concursos (pp. 109-122). Buenos Aires: Legis, Instituto Argentino de Derecho Comercial.

Brunetti, A. (2001). Sociedad anónima. México D.F.: Editorial Jurídcia Universitaria.

Cabanellas, G. (2009). El problema del llamado Gobierno Corporativo en la realidad societaria argentina. En G. d. Tartiére. Mercado de capitales. Buenos Aires: Heliasta.

Córdoba, P. A. (2000). El gobierno de la empresa y el derecho. (U. E. Colombia. Ed.). Revista de Derecho Privado, 5, 180.

De Solá, F. (1963). Tratado de derecho comercial comparado. Barcelona: Montaner y Simón.

Halperin, I., \& Otaegui, J. C. (1999). Sociedades anónimas. Buenos Aires: Depalma. Hopt, K. J. (2010). Estudios de derecho de sociedades y del mercado de valores. Barcelona: Marcial Pons.

Ibañez, J. W., \& Fernández, J. L. (2002). Etica y mercado de valores. Madrid: Marcial Pons.

Morgestein, W. I. (2011). El concepto de interés social y su impacto en el derecho colombiano. E-mercatoria, 4-20.

Narváez, J. I. (2002). Teoria general de las sociedades. Bogotá: Legis.

Nissen, R. (2010). Ley de sociedades comerciales (vol. 3). Bueno Aires: Editorial Astrea. 
Organización Económica para la Cooperación y el Desarrollo. (2004). Principios de gobierno corporativo.

Reyes, F. (2005). Derecho societario en los Estados Unidos. Intruducción comparada. Bogotá: Legis.

Reyes, F. (2006). Derecho societario. Bogotá: Temis.

Reyes, F. (2012). Análisis económico del derecho societario. Bogotá: Pontificia Univesidad Javeriana Facultad de Ciencias Jurídicas, Grupo Bancolombia, Grupo Editorial Ibañez.

Smith, A. (1997). Una investigación sobre la naturaleza y causa de la riqueza de las naciones ( $9^{\text {a }}$ reimpresión). México: Fondo de Cultura Económica.

Stiglitz, J. (2003). Los felices 90: La semilla de la destruccion . Madrid: Rosés S.A.

Superintendencia Financiera, Colombia. (2010). Documento conceptual de gobierno corporativo.

Normas jurídicas colombianas consultadas

Decreto 410 de 1971.

Decreto 2555 de 2010.

Decreto Único Reglamentario 1074 de 2015.

Ley 222 de 1995

Bolsa de Valores de Colombia

Resolución 41 de marzo 23 de 2006.

Superintendencia de Sociedades

Auto número 801-6851 de mayo 9 de 2014.

Auto número 801-7259 de mayo 19 de 2014.

Auto número 801-11097 de agosto 5 de 2014.

Auto número 801-17880 de diciembre 4 de 2014.

Auto número 800-3504 de febrero 25 de 2015.

Circular Externa 20, de noviembre 4 de 1997.

Oficio 220-066699 de Mayo 26 de 2011

Oficio 220-015289 de marzo 11 de 2012.

Oficio 220-140389 de noviembre 27 de 2012.

Sentencia 800-29 de mayo 14 de 2014.

Sentencia 801-35 de julio 9 de 2013. 
Superintendencia Financiera de Colombia

Concepto 95017190-0 del 15 de mayo de 1995. Superintendente delegado para instituciones financieras.

Concepto 2007059749-001 de diciembre 28 de 2007. Superintendente delegado para instituciones financieras. 